\title{
CHANGES IN WHOLE BLOOD LACTATE LEVELS DURING CARDIOPULMONARY BYPASS FOR SURGERY FOR CONGENITAL CARDIAC DISEASE: AN EARLY INDICATOR OF MORBIDITY AND MORTALITY
}

Ricardo Munoz, MD

Peter C. Laussen, $\mathrm{MBBS}^{\mathrm{b}}$

Guillermo Palacio, MD

Lynne Zienko, BS ${ }^{\mathrm{b}}$

Gary Piercey, $\mathrm{BS}^{\mathrm{b}}$

David L. Wessel, MD ${ }^{\mathrm{a}}$
Objective: Our objective was to evaluate the change in lactate level during cardiopulmonary bypass and the possible predictive value in identifying patients at high risk of morbidity and mortality after surgery for congenital cardiac disease. Methods: We prospectively studied lactate levels in 174 nonconsecutive patients undergoing cardiopulmonary bypass during operations for congenital cardiac disease. Arterial blood samples were taken before cardiopulmonary bypass, during cardiopulmonary bypass (cooling and rewarming), after cardiopulmonary bypass, and during admission to the cardiac intensive care unit. Complicated outcomes were defined as open sternum as a response to cardiopulmonary instability, renal failure, cardiac arrest and resuscitation, extracorporeal membrane oxygenation, and death. Results: The largest increment in lactate level occurred during cardiopulmonary bypass. Lactate levels decreased between the postbypass period and on admission to the intensive care unit. Patients who had circulatory arrest exhibited higher lactate levels at all time points. Nonsurvivors had higher lactate levels at all time points. A change in lactate level of more than $3 \mathrm{mmol} / \mathrm{L}$ during cardiopulmonary bypass had the optimal sensitivity $(82 \%)$ and specificity $(\mathbf{8 0 \%})$ for mortality, although the positive predictive value was low. Conclusions: Hyperlactatemia occurs during cardiopulmonary bypass in patients undergoing operations for congenital cardiac disease and may be an early indicator for postoperative morbidity and mortality. (J Thorac Cardiovasc Surg 2000;119:155-62)
$\mathrm{R}$ eliable indicators of morbidity and mortality after operations for congenital cardiac disease have been difficult to determine. Continuous invasive monitoring is often limited, particularly in neonates and infants. Nevertheless, the development of a reliable indicator of outcome is an important goal, not only to improve mor-

From the Departments of Cardiology and Anesthesia, ${ }^{\mathrm{b}}$ Children's Hospital, Boston, and the Departments of Pediatrics and Anesthesia, ${ }^{\mathrm{a}}$ Harvard Medical School, Boston, Mass.

Supported in part by funds from the Nova Biomedical Corporation (Waltham, Mass) and the Boston Children's Heart Foundation.

Presented at the Forty-eighth Annual Scientific Session of the American College of Cardiology, New Orleans, La, March 7-10, 1999.

Received for publication March 25, 1999; revisions requested May 18, 1999; revisions received Sept 7, 1999; accepted for publication Sept 20, 1999.

Address for reprints: Ricardo Munoz, MD, Cardiac ICU Office, FA105, Children's Hospital, 300 Longwood Ave, Boston, MA 02115 (E-mail: munoz_r@a1.tch.harvard.edu).

Copyright $\odot 2000$ by Mosby, Inc.

$0022-5223 / 2000 \$ 12.00+0 \quad \mathbf{1 2 / 1 / 1 0 3 1 5 6}$ bidity and mortality, but also to maintain cost-effective care.

Hyperlactatemia on admission to the cardiac intensive care unit (CICU) has been proposed as a potentially sensitive and specific marker for adverse outcome. Data from recent studies are summarized in Table I. $^{1-5}$ As demonstrated in the table, no specific lactate level has been a consistent indicator of outcome. Although the peak lactate level may indicate low cardiac output or reduced tissue oxygen extraction, the change in lactate level over time may be a more reliable marker of the response to therapeutic interventions and subsequent outcome. The studies cited have primarily examined lactate levels on admission to the CICU, yet the initial stimulus for lactate production may occur during cardiopulmonary bypass (CPB). The duration of $\mathrm{CPB}$, duration of circulatory arrest, the degree of hypothermia, duration of cooling and rewarming, $\mathrm{pH}$ management strategy, and hematocrit value are all potential factors that may contribute to hypoperfusion during CPB. In addition, surgical considerations such as impaired 
Table I. Hyperlactatemia on ICU admission: PPV, sensitivity, and specificity for morbidity and mortality

\begin{tabular}{|c|c|c|c|c|c|}
\hline \multirow[b]{2}{*}{ Author } & \multicolumn{2}{|c|}{ Patients } & \multirow[b]{2}{*}{ Age } & \multirow{2}{*}{$\begin{array}{l}\text { Lactate on ICU admission } \\
\text { associated with complications } \\
\text { including death }(\mathrm{mmol} / \mathrm{L})\end{array}$} & \multirow[b]{2}{*}{ Comment } \\
\hline & No. & Died & & & \\
\hline Siegel et al, $1995^{1}$ & 41 & 7 & 2 mo-16 y & $6.9 \pm 0.8^{*}$ & Range 3.9 to 10.2 \\
\hline Shemie et al, $1996^{2}$ & 109 & 8 & $1 \mathrm{~d}-19 \mathrm{y}$ & $13.7 \pm 8.9^{*}$ & $\begin{array}{l}>5 \mathrm{mmol} / \mathrm{L}: 75 \% \text { sensitivity, } 84 \% \text { specificity } \\
\text { for complication }\end{array}$ \\
\hline Cheifetz et al, $1997^{3}$ & 48 & 6 & $<12 \mathrm{mo}$ & $13.7 \pm 2.4^{*}$ & $<7 \mathrm{mmol} / \mathrm{L}: 100 \%$ sensitivity for survival \\
\hline Hatherill et al, $1997^{4}$ & 99 & 9 & $0.4-31 \mathrm{mo}$ & $8.7(1.9-17.6)^{\dagger}$ & $\begin{array}{l}>6 \mathrm{mmol} / \mathrm{L} ; 50 \% \text { sensitivity, } 90 \% \text { specificity } \\
\text { for complication. PPV } 68 \%\end{array}$ \\
\hline Duke et al, $1997^{5}$ & 90 & 4 & $0.5-5.75 \mathrm{mo}$ & $3.0(2.1-4.9)^{\dagger}$ & $\begin{array}{c}>4.5 \mathrm{mmol} / \mathrm{L} \text { on ICU admission, odds ratio } \\
(95 \% \mathrm{CI}) \text { for complication } 5.1(1.2-21.1)\end{array}$ \\
\hline
\end{tabular}

$I C U$, Intensive care unit; $P P V$, positive predictive value; $C I$, confidence interval.

*Mean \pm standard deviation.

'Median (range)

venous drainage or anatomic lesions characterized by reduced splanchnic flow or excessive systemic runoff may limit perfusion. Finally, the systemic inflammatory response to $\mathrm{CPB}$, which is heightened in neonates and infants, may also impair organ perfusion and perhaps, more specifically, tissue oxygen extraction.

This study examines the change in whole blood lactate level during $\mathrm{CPB}$ and the possible role in identifying patients at high risk for morbidity and mortality after operations for congenital cardiac disease.

\section{Patients and methods}

The study was approved by the Institutional Review Board of Children's Hospital, Boston, and written informed consent was obtained from parents or from subjects older than 17 years of age. A prospective observational study of 174 nonconsecutive patients undergoing CPB with or without circulatory arrest for surgery for congenital cardiac disease was conducted between March 1996 and April 1998. This group represents $13 \%$ of all patients who underwent $\mathrm{CPB}$ at our institution during the study period. Patients for the study were selected by convenience sampling, without randomization or control of surgical procedure, conduct of anesthesia, or CPB management. The patients enrolled were primarily either in the CICU before the operation or had been admitted to the hospital before the operation. Thus there was a selection bias toward patients with more complicated congenital defects and operations.

After induction of anesthesia and placement of an intraarterial catheter, $1 \mathrm{~mL}$ of arterial blood was collected into a heparinized blood gas syringe and immediately analyzed on the Ultra $\mathrm{C}$ analyzer (Nova Biomedical, Waltham, Mass) for blood gas, lactate, hematocrit, electrolytes, magnesium, $\mathrm{Ca}^{2+}$, and glucose. Quality controls were performed on the analyzer before laboratory determinations. Samples were not drawn at specific time points, but rather within 5 time intervals: before $\mathrm{CPB}$, during cooling on $\mathrm{CPB}$, during rewarming on $\mathrm{CPB}$, immediately after $\mathrm{CPB}$ in the operating room, and after admission to the CICU. The lactate level in the extracorporeal circuit after initial priming and before $\mathrm{CPB}$ was not measured.

Differences in lactate levels related to patient age, weight, and diagnosis were examined. To examine the effect of patient diagnosis and surgical complexity on serum lactate level and outcome, we separated patients into complexity categories as previously described by Jenkins and colleagues. ${ }^{6}$ This classification does not include heart transplantation, and those patients in our study $(\mathrm{n}=3)$ were excluded from the analysis. Patient mortality and the prevalence of postoperative complications for each of the 4 complexity categories relative to the change in lactate were examined.

On CICU admission, the severity of illness for each patient was assessed by means of the Pediatric Severity of Illness score (PRISM III). ${ }^{7}$ Patients were categorized as having a complicated postoperative outcome if they demonstrated one or more of the following events: (1) renal insufficiency with a serum creatinine level of more than $1.5 \mathrm{mg} / \mathrm{dL}$ in the CICU, (2) cardiac arrest and resuscitation, (3) extracorporeal membrane oxygenation, (4) open sternum as a response to cardiopulmonary instability either in the operating room or after emergency chest reopening in the CICU, and (5) death. In addition to these adverse events, the duration of mechanical ventilation and length of CICU stay were also examined.

The change in lactate during CPB was defined as the difference between baseline (median 47 minutes before CPB) and the first lactate value obtained after CPB (median 9 minutes). Duration of CPB was defined as the total elapsed time from the institution of CPB until discontinuation of CPB at the end of surgical repair. This period included circulatory arrest time. During CPB, the change in lactate level was evaluated relative to duration of $\mathrm{CPB}$, duration of circulatory arrest, duration of cooling, duration of rewarming, nadir temperature, blood gas strategy, and hematocrit. The relationships between patient complications including death and the change in lactate level during CPB and the absolute lactate level on admission to the CICU were examined.

Statistical analysis. Because they are not normally distrib- 
Table II. Categories of surgical complexity, surgical description, mortality, and complications

\begin{tabular}{|c|c|c|c|c|c|}
\hline \multirow[b]{2}{*}{ Category } & \multirow[b]{2}{*}{ Surgical description (n) } & \multicolumn{2}{|c|}{ Died } & \multicolumn{2}{|c|}{ Complication } \\
\hline & & No. & $\%$ & No. & $\%$ \\
\hline \multirow[t]{2}{*}{$1(n=26)$} & $\operatorname{ASD}(n=23)$ & 0 & 0 & 0 & 0 \\
\hline & $\mathrm{PAB}(\mathrm{n}=3)$ & & & & \\
\hline \multirow[t]{8}{*}{$2(\mathrm{n}=56)$} & Open valvotomy $(\mathrm{n}=3)$ & 2 & 3.6 & 4 & 7.1 \\
\hline & Subaortic stenosis resection $(\mathrm{n}=2)$ & & & & \\
\hline & $\operatorname{VSD}(\mathrm{n}=25)$ & & & & \\
\hline & $\operatorname{AVC}(\mathrm{n}=6)$ & & & & \\
\hline & TOF $(n=12)$ & & & & \\
\hline & Thoracic vessel repair, prosthesis $(n=2)$ & & & & \\
\hline & Septal surgery, unspecified $(n=4)$ & & & & \\
\hline & Operations adjacent to heart valves $(\mathrm{n}=2)$ & & & & \\
\hline \multirow[t]{7}{*}{$3(n=45)$} & Valve replacement $(\mathrm{n}=3)$ & 1 & 2.2 & 10 & 22 \\
\hline & $\operatorname{TAPVR}(\mathrm{n}=1)$ & & & & \\
\hline & Truncus arteriosus $(n=4)$ & & & & \\
\hline & RV-PA conduit $(\mathrm{n}=18)$ & & & & \\
\hline & LV-Ao conduit $(\mathrm{n}=2)$ & & & & \\
\hline & Cavopulmonary shunt $(\mathrm{n}=10)$ & & & & \\
\hline & AP window $(n=7)$ & & & & \\
\hline \multirow[t]{4}{*}{$4(\mathrm{n}=44)$} & $\operatorname{ASO}(n=14)$ & 10 & 23 & 16 & 36 \\
\hline & Fontan $(n=14)$ & & & & \\
\hline & Norwood $(n=16)$ & & & & \\
\hline & $P$ value ${ }^{*}$ & \multicolumn{2}{|c|}{.001} & \multicolumn{2}{|c|}{$<.001$} \\
\hline
\end{tabular}

$A S D$, Atrial septal defect; $P A B$, pulmonary artery band; VSD, ventricular septal defect; $A V C$, atrioventricular canal; TOF, tetralogy of Fallot; TAPVR, total anomalous pulmonary venous connection; $R V$, right ventricle; $P A$, pulmonary artery; $L V$, left ventricle; $A o$, aorta; $A P$, aortopulmonary; $A S O$, arterial switch operation. Heart transplants $(\mathrm{n}=3$, deaths $=1)$ were excluded from the surgical categories.

${ }^{*}$ Comparing proportions of complications and mortality among categories of surgical complexity by the Fisher exact test.

Table III. Categories of surgical complexity and lactate levels at each time point of the perioperative period

\begin{tabular}{llllll}
\hline Category & Baseline & Cooling & Rewarming & After CPB & CICU admission \\
\hline 1 & 1.2 & 1.8 & 2.2 & 2.2 & 2.0 \\
& $(0.9-1.6)$ & $(1.6-2.3)$ & $(1.9-3.7)$ & $(1.8-3.6)$ & $(1.2-3.4)$ \\
2 & 1.1 & 1.6 & 2.3 & 2.3 & 2.1 \\
\\
3 & $(0.8-1.4)$ & $(1.1-2.4)$ & $(1.6-3.5)$ & $(1.6-3.4)$ & $(1.3-2.7)$ \\
& 1.1 & 1.7 & 2.3 & 2.7 & 1.9 \\
4 & $(0.7-1.4)$ & $(1.2-2.3)$ & $(1.8-4.5)$ & $(2.0-4.7)$ & $(1.4-4.5)$ \\
& 1.5 & 2.5 & 4.9 & 5.1 & 4.3 \\
& $(1.0-2.6)$ & $(1.7-4.5)$ & $(2.2-6.5)$ & $(2.4-6.5)$ & $(2.0-7.8)$ \\
\hline
\end{tabular}

Data are expressed as median (25th and 75th percentiles). $C P B$, Cardiopulmonary bypass; $C I C U$, cardiac intensive care unit.

uted, lactate levels were analyzed by means of nonparametric methods. Medians were compared by means of the Wilcoxon signed-rank test for paired data, the rank sum test for 2 independent groups, and the Kruskal-Wallis test for more than 2 groups. The Wilcoxon signed-rank test was used to compare median lactate levels over time, with a Bonferroni correction for multiple comparisons. The Spearman rank correlation coefficient was used to look for relationships between lactate change during $\mathrm{CPB}$ and continuous measures. The Fisher exact test was used to compare proportions. The following outcome variables were analyzed: PRISM III score, duration of mechanical ventilation, CICU stay, complications, and mortality. To control for other covariates, we used linear regression methods for continuous outcomes and logistic regression for binary outcomes. A log transformation was used for continuous outcomes that were not normally distributed. The receiver operator characteristic curve was used to optimize sensitivity and specificity when using a change of lactate level during CPB to predict mortality. Analyses were performed with the Stata statistical package (Stata Corporation, College Station, Tex).

\section{Results}

For the 174 patients studied (68 female and 106 male patients), the median age was 0.8 years with a range of 1 day to 39.8 years; the median weight was $7.3 \mathrm{~kg}$ (range 1.9-94 kg). 
Table IV. Age, weight, and CPB characteristics between survivors, with and without complications, and nonsurvivors

\begin{tabular}{|c|c|c|c|c|}
\hline & $\begin{array}{l}\text { Survivors without } \\
\text { complications } \\
(n=142)\end{array}$ & $\begin{array}{l}\text { Survivors with } \\
\text { complications } \\
\quad(n=18)\end{array}$ & $\begin{array}{l}\text { Nonsurvivors } \\
\quad(n=14)\end{array}$ & $\mathrm{P}$ value ${ }^{*}$ \\
\hline Age & $\begin{array}{c}1.4 \mathrm{y} \\
(75 \mathrm{~d}-6.7 \mathrm{y})\end{array}$ & $\begin{array}{l}12 \mathrm{~d} \\
(5 \mathrm{~d}-1.7 \mathrm{y})\end{array}$ & $\begin{array}{l}5 \mathrm{~d} \\
(2-18 \mathrm{~d})\end{array}$ & $<.001$ \\
\hline Weight (kg) & $\begin{array}{l}9 \\
(4.4-17.3)\end{array}$ & $\begin{array}{l}3.6 \\
(3.2-9.7)\end{array}$ & $\begin{array}{l}2.8 \\
(2.3-4.5)\end{array}$ & $<.001$ \\
\hline CPB time (min) & $\begin{array}{l}88.5 \\
(62-123)\end{array}$ & $\begin{array}{l}127 \\
(109-160)\end{array}$ & $\begin{array}{l}173.5 \\
(124-219)\end{array}$ & $<.001$ \\
\hline Circulatory arrest time $(\mathrm{min})^{\dagger}$ & $\begin{array}{l}22 \\
(10-38)\end{array}$ & $\begin{array}{l}41 \\
(31-54)\end{array}$ & $\begin{array}{l}44 \\
(16-51)\end{array}$ & .02 \\
\hline Duration of cooling (min) & $\begin{array}{l}20 \\
(12-30)\end{array}$ & $\begin{array}{l}31 \\
(18-46)\end{array}$ & $\begin{array}{l}26 \\
(20-50)\end{array}$ & .06 \\
\hline Duration of rewarming (min) & $\begin{array}{l}27 \\
(20-33)\end{array}$ & $\begin{array}{l}33 \\
(27-39)\end{array}$ & $\begin{array}{l}43.5 \\
(35-50)\end{array}$ & $<.001$ \\
\hline Hematocrit cooling (\%) & $\begin{array}{l}24 \\
(21-26)\end{array}$ & $\begin{array}{l}23 \\
(21-28)\end{array}$ & $\begin{array}{l}25.5 \\
(22-28)\end{array}$ & $>.2$ \\
\hline Hematocrit rewarming (\%) & $\begin{array}{l}26 \\
(22-29)\end{array}$ & $\begin{array}{l}27 \\
(24-30)\end{array}$ & $\begin{array}{l}28 \\
(27-32)\end{array}$ & .02 \\
\hline
\end{tabular}

Data are expressed as median (25th and 75 th percentiles). $C P B$, Cardiopulmonary bypass.

*Comparison of all 3 groups by Kruskal-Wallis test.

'Median for the number of patients undergoing circulatory arrest in each group, that is, 39 of 142 survivors without complications, 9 of 18 survivors with complications, and 13 of 14 nonsurvivors.

Table V. Median lactate levels between survivors, with and without complications, and nonsurvivors

\begin{tabular}{|c|c|c|c|c|}
\hline & $\begin{array}{l}\text { Survivors without } \\
\text { complications } \\
(n=142)\end{array}$ & $\begin{array}{l}\text { Survivors with } \\
\text { complications } \\
\quad(n=18)\end{array}$ & $\begin{array}{l}\text { Nonsurvivors } \\
\quad(n=14)\end{array}$ & $\mathrm{P}$ value ${ }^{*}$ \\
\hline Baseline & $\begin{array}{l}1.1 \\
(0.8-1.5)\end{array}$ & $\begin{array}{l}1.2 \\
(0.9-2.4)\end{array}$ & $\begin{array}{l}2.0 \\
(1.3-2.7)\end{array}$ & .01 \\
\hline Cooling & $\begin{array}{l}1.7 \\
(1.2-2.4)\end{array}$ & $\begin{array}{l}2.3 \\
(1.9-3.1)\end{array}$ & $\begin{array}{l}4.1 \\
(2.4-4.9)\end{array}$ & $<.001$ \\
\hline Rewarming & $\begin{array}{l}2.3 \\
(1.6-3.7)\end{array}$ & $\begin{array}{l}4.1 \\
(2.3-5.4)\end{array}$ & $\begin{array}{l}7.4 \\
(4.2-7.8)\end{array}$ & $<.001$ \\
\hline After CPB & $\begin{array}{l}2.3 \\
(1.8-4.1)\end{array}$ & $\begin{array}{l}5.1 \\
(2.2-6.1)\end{array}$ & $\begin{array}{l}7.4 \\
(5.1-10.7)\end{array}$ & $<.001$ \\
\hline$\Delta$ Lactate during $\mathrm{CPB}$ & $\begin{array}{l}1.3 \\
(0.7-2.3)\end{array}$ & $\begin{array}{l}3.1 \\
(1.2-4.5)\end{array}$ & $\begin{array}{l}5.0 \\
(3.1-8)\end{array}$ & $<.001$ \\
\hline CICU admission & $\begin{array}{l}2.0 \\
(1.3-3.2)\end{array}$ & $\begin{array}{l}4.6 \\
(2.1-8.3)\end{array}$ & $\begin{array}{l}8.5 \\
(7.8-20)\end{array}$ & $<.001$ \\
\hline
\end{tabular}

Data are expressed as median (25th and 75th percentiles). $\triangle$ Lactate, Change in lactate level; $C P B$, cardiopulmonary bypass; $C I C U$, cardiac intensive care unit.

*Comparison of all 3 groups by Kruskal-Wallis test.

The change in lactate level during CPB increased with surgical complexity $(P=.002)$. With increasing surgical complexity, there was an increase in postoperative complications, as expected $(P<.001$, Table II). Summary statistics for the lactate levels for each surgical complexity category after induction of anesthesia, cooling on $\mathrm{CPB}$, rewarming on $\mathrm{CPB}$, immediately after CPB, and on admission to the CICU are shown in Table III.

Change in lactate level during CPB. The median age, weight, and CPB characteristics for patients without complications, patients who died, and patients who had at least 1 postoperative complication are shown in Table IV. An increase in median lactate level was noted from baseline versus cooling $(P<.0001)$, cooling versus rewarming $(P<.0001)$, and rewarming versus the post-CPB period $(P=$ .0002 ) and a decrease in lactate level between the immediate post-CPB period and admission to the CICU $(P=.01)$ (Fig 1). All differences remained statistically 


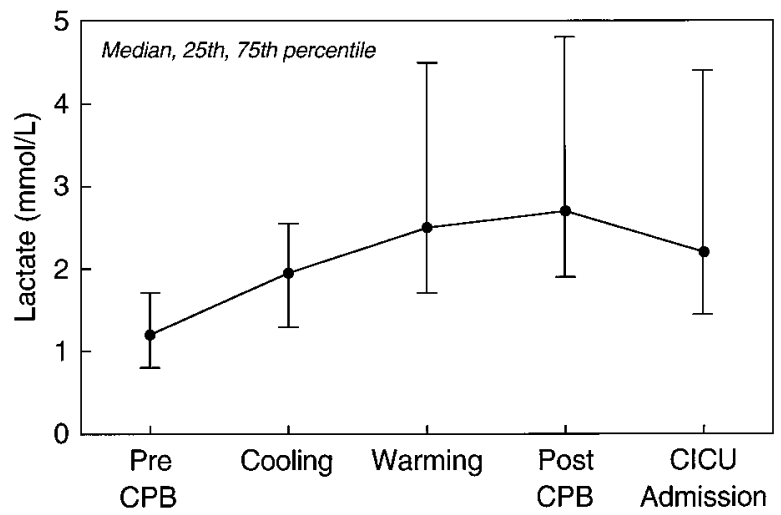

Fig 1. Median, 25th, and 75th percentiles of lactate levels at each time point of the perioperative period. $C P B$, Cardiopulmonary bypass; $C I C U$, cardiac intensive care unit.

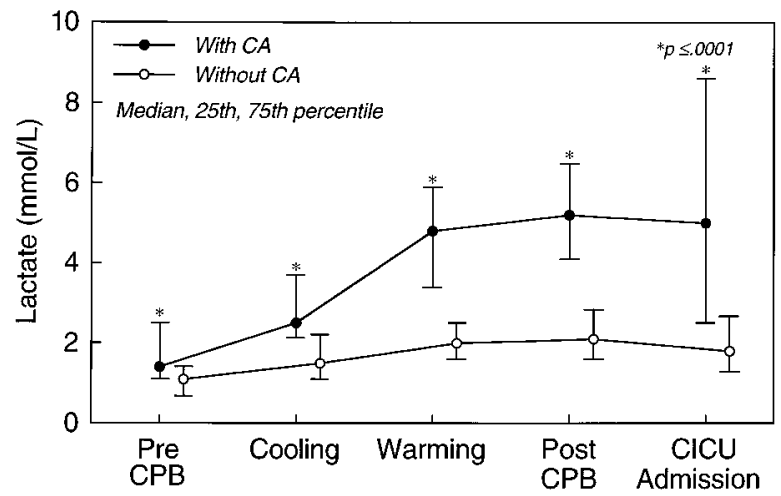

Fig 2. Difference in median, 25th, and 75th percentiles of lactate levels between patients with and without circulatory arrest at each time point of the perioperative period. $C P B$, Cardiopulmonary bypass; $C I C U$, cardiac intensive care unit; $C A$, circulatory arrest.

significant after use of the Bonferroni correction for multiple comparisons.

The duration of CPB and circulatory arrest was positively correlated with a change in lactate during $\mathrm{CPB}$ $\left(P<.0001, r_{s}=0.43\right.$, and $P=.0002, r_{s}=0.47$, respectively). The correlation between duration of circulatory arrest and a lactate change during CPB remained significant after excluding the 16 patients who had undergone a Norwood procedure $(P=.003, r s=$ $0.43)$. Patients who had circulatory arrest $(n=61)$ had a higher median lactate level at all time points than did patients without circulatory arrest $(\mathrm{n}=113)$ (Fig 2). Again, all differences remain statistically significant after application of a Bonferroni correction. By univariate analysis, there was no relationship between

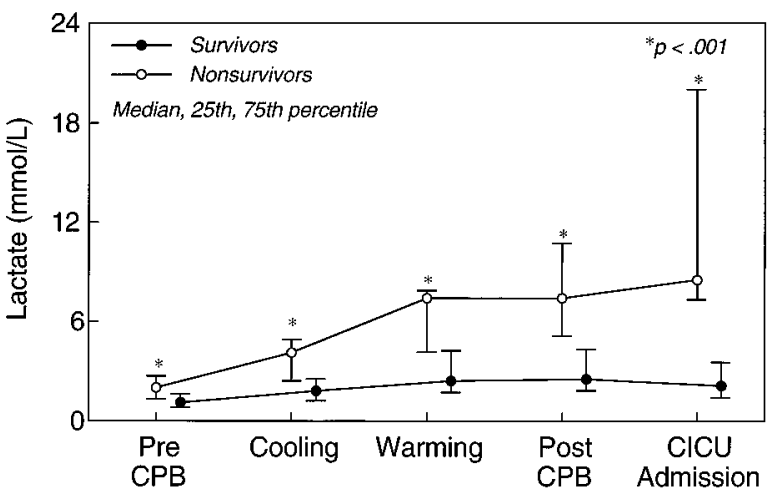

Fig 3. Difference in median, 25th, and 75th percentiles of lactate levels between survivors and nonsurvivors at each time point of the perioperative period. $C P B$, Cardiopulmonary bypass; $C I C U$, cardiac intensive care unit.

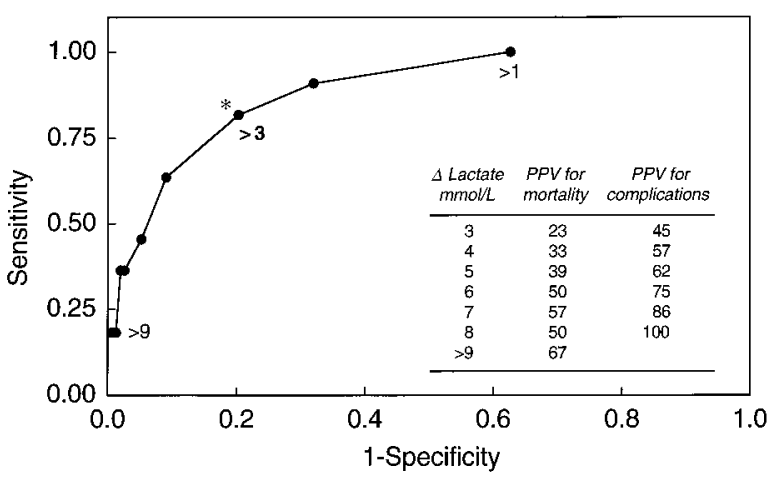

Fig 4. Receiver operator characteristic curve showing sensitivity and ( 1 - specificity) of a change $(\Delta)$ in whole blood lactate levels during cardiopulmonary bypass $(C P B)$ for mortality. Positive predictive value $(P P V)$ of a lactate change during cardiopulmonary bypass for mortality and complications.

the change in lactate level and nadir temperature, lowest hematocrit value, or blood gas strategy during CPB.

The median lactate levels for each time point and the changes in lactate during CPB for survivors without complications $(n=142)$, patients who died $(n=14)$, and those who had at least 1 postoperative complication (n $=18$ ) are shown in Table V. Nonsurvivors exhibited a higher median lactate level at all time points than did survivors $(P<.001)$ (Fig 3). On the basis of the receiver operator characteristic analysis, a change in lactate level of more than $3 \mathrm{mmol} / \mathrm{L}$ had a sensitivity of $82 \%$ and a specificity of $80 \%$ for mortality but a low positive predictive value of $23 \%$. This change in lactate level had a positive predictive value of $45 \%$ for complications. 
Table VI. PRISM III score, duration of mechanical ventilation, CICU stay, and postoperative complications between survivors, with and without complications, and nonsurvivors

\begin{tabular}{lcccc}
\hline & $\begin{array}{c}\text { Survivors without } \\
\text { complications } \\
(n=142)\end{array}$ & $\begin{array}{c}\text { Survivors with } \\
\text { complications } \\
(n=18)\end{array}$ & $\begin{array}{c}\text { Nonsurvivors } \\
(n=14)\end{array}$ & $\begin{array}{c}12.5 \\
(8-14)\end{array}$ \\
\hline PRISM III score & 5 & 7 & 375 & $(96-957)$ \\
Mechanical ventilation (h) & $(2-7)$ & 158 & 408 & $<.001$ \\
Duration CICU stay (h) & 20 & $(28-260)$ & $(96-957)$ \\
Renal insufficiency (n) & $(8.8-46.5)$ & 223 & 3 \\
Cardiac arrest off CPB (n) & 48 & $(98-361)$ & 2 \\
ECMO (n) & $(25-90)$ & 2 & 2 \\
Open sternum (n) & - & 1 & 8 & $<.001$ \\
\hline
\end{tabular}

Data are expressed as median (25th and 75th percentiles) for PRISM III score, duration of mechanical ventilation, and duration of CICU stay. CPB, Cardiopulmonary bypass; $C I C U$, cardiac intensive care unit; $E C M O$, extracorporeal membrane oxygenation.

${ }^{*}$ Comparison of all 3 groups by Kruskal-Wallis test.

Progressive increments in the change in lactate level during CPB increased the positive predictive value for mortality and complications as shown in Fig 4.

Lactate level on admission to the CICU. The PRISM III score on admission to the CICU, incidence of complications, duration of mechanical ventilation, and duration of stay in the CICU for survivors and nonsurvivors are shown in Table VI. Lactate change during CPB was correlated with higher PRISM III score on CICU admission $\left(P<.0001, r_{s}=0.43\right)$, longer intubation time $\left(P<.0001, r_{s}=0.47\right)$, and longer CICU stay $\left(P=.0001, r_{s}=0.45\right)$. By means of multivariable regression models controlling for CPB time, circulatory arrest, Norwood procedure, and neonate status, a change in lactate level during CPB remained significantly associated only with higher PRISM III score on admission to the CICU $(P=.05)$. Although not statistically significant, there was a trend for a larger change in lactate during CPB to be associated with mortality $(P$ $=.13)$ and complications $(P=.06)$.

\section{Discussion}

Although previous reports have noted an association between hyperlactatemia on CICU admission and morbidity and mortality, ${ }^{1-5}$ our study demonstrates that the increase in lactate occurs during CPB and this may be an early indicator of outcome. In this study, the increase in lactate during CPB was more common in patients with complex anatomy or surgical procedures, was related to the duration of CPB and circulatory arrest, and was associated with a higher PRISM III score on admission to the CICU, longer duration of mechanical ventilation, and longer CICU stay.
An absolute lactate level or range has not been defined that correlates accurately with morbidity and mortality, and it is likely that the change in lactate over time is a better marker of patient outcome. Hatherill and associates ${ }^{4}$ reported that a serum lactate level of more than $6 \mathrm{mmol} / \mathrm{L}$ on CICU admission in children after surgery for congenital cardiac disease had a low positive predictive value for mortality. In addition, Hatherill and associates demonstrated a wide range of CICU admission lactate levels between survivors (0.613. $6 \mathrm{mmol} / \mathrm{L})$ and nonsurvivors $(1.9-17.6 \mathrm{mmol} / \mathrm{L})$ in patients undergoing complex surgical repairs. However, children who had a complicated postoperative course (defined as end-organ injury) had higher median initial serum lactate levels than did those patients who had an uncomplicated course. Similar lactate levels indicating a complicated postoperative course have also been reported by $\mathrm{Shemie}^{2}$ and Duke and coworkers. ${ }^{5}$

Hyperlactatemia measured on admission to the CICU has been significantly correlated with the duration of CPB and circulatory arrest, an increased alveolar-arterial oxygen tension gradient, duration of inotropic support, and duration of mechanical ventilation., 1,2,4,5 Although an isolated lactate level of more than 6 $\mathrm{mmol} / \mathrm{L}$ in the CICU may be a useful indicator for a complicated postoperative course, it does not discriminate between survivors and nonsurvivors. Our study demonstrates that the onset of hyperlactatemia occurs in the operating room during $\mathrm{CPB}$, and this change in lactate concentration correlated with a higher PRISM III score and longer duration of mechanical ventilation and CICU stay. 
An increase in lactate concentration may be the result of diminished tissue perfusion and oxygen delivery, decreased oxygen extraction, and decreased hepatic lactate clearance. ${ }^{8}$ Operations for biventricular repair or palliation of many defects are often complex and prolonged procedures, necessitating an increased duration of deep hypothermic CPB with or without circulatory arrest. In addition, the disparity between the prime volume of the CPB circuit and patient's blood volume in neonates and infants means that the effects of hemodilution are magnified. A decrease in hematocrit value and oncotic pressure may impair oxygen delivery, and a fall in systemic vascular resistance may decrease organ perfusion. ${ }^{9}$ Further, the increased exposure of circulating blood in neonates and infants to the nonendothelialized surface of the CPB circuit heightens the systemic inflammatory response, and the release of cytokines and oxygen-derived free radicals may directly injure tissue and alter microcirculatory flow.

The adequacy of perfusion during hypothermic CPB is generally monitored by means of indirect or global indices of perfusion. The flow rate and perfusion pressure during CPB varies according to the level of hypothermia, the anticipated surgical complexity, and the duration of repair. The urine output during CPB may be an indicator of renal perfusion, although an association between urine output during CPB and patient morbidity has not been noted. A fall in mixed venous oxygen saturation during CPB may occur even though flow rate and perfusion pressure appear adequate. This reflects increased oxygen extraction from either inadequate tissue perfusion or increased oxygen demand, such as during the rewarming process or under light levels of anesthesia. A mismatch between oxygen demand and delivery may occur regionally, but regional blood flow is difficult to monitor during CPB. The relative cardiac output, vasomotor tone of various organs, and patency of the microcirculation are altered during bypass. In addition, regional metabolic demands may be increased because of nonhomogeneous cooling and rewarming and as a result of the oxygen debt incurred from hypoperfusion during CPB. The inflammatory response with release of cytokines and the release of endogenous stress hormones that occur during hypothermic CPB will also increase regional metabolic demands. ${ }^{10,11}$

Although nonspecific, an increase or change in lactate level during CPB may be a marker of regional hypoperfusion or increased metabolic demand. The organs most likely to produce lactate in response to hypoperfusion or decreased oxygen extraction include the brain, gut, liver, kidneys, and skeletal muscle. ${ }^{12-14}$
Changes in cerebral blood flow and cerebral metabolic rate in response to deep hypothermic circulatory arrest have been described. ${ }^{15}$ Methods for monitoring cerebral oxygen disturbance during CPB include the measurement of jugular venous bulb oxygen saturation and lactate, and measurement of the redox state of the brain by near-infrared spectroscopy. These indices have not been correlated with a change in blood lactate levels.

The integrity of the gastrointestinal tract may also be altered during CPB. Studies examining the effect of $\mathrm{CPB}$ on splanchnic oxygenation and blood flow have demonstrated that significant mucosal hypoperfusion may occur. ${ }^{9,16-18}$ This may cause an increase in permeability across the bowel wall, contributing to an increase in endotoxin and cytokine levels after CPB. Splanchnic blood flow may be influenced by a number of factors. Anatomic defects or surgical repairs associated with diastolic runoff from an aortopulmonary communication, such as a patent ductus arteriosus or modified Blalock-Taussig shunt, may reduce splanchnic perfusion. In addition, the splanchnic vascular bed is influenced by various circulating humoral mediators; catecholamines, angiotensin II, and vasopressin cause splanchnic vasoconstriction, and histamine, prostaglandin $\mathrm{E}_{2}$, and bradykinin have vasodilator properties. ${ }^{19}$ The blood gas management during hypothermic CPB may also influence splanchnic vascular tone with an increase in carbon dioxide tension causing an increase in blood flow. Finally, intestinal mucosal edema may occur during hypothermic CPB, which would potentially limit splanchnic perfusion and oxygen extraction.

No interventions during CPB were made in our patients in response to an increase in lactate level. In addition, the anesthetic technique varied among patients, and the specific influence of anesthesia on lactate level could not be examined. Nevertheless, early recognition of patients at risk for the development of hyperlactatemia associated with morbidity and mortality may allow intervention in a timely manner to reduce their susceptibility to injury. Although we were unable to determine a relation between a change in lactate and $\mathrm{CPB}$ variables such as hematocrit value and $\mathrm{pH}$ management, potential interventions that may alter organ perfusion and tissue oxygen use during CPB include the following: (1) manipulation of perfusion pressure and flow rates, (2) level of hypothermia and duration of cooling and rewarming, (3) alteration in the circuit prime to ensure optimal hematocrit value and oncotic pressure, (4) ultrafiltration during rewarming or after separation from $\mathrm{CPB}$, and (5) the use of agents to specifically modify the systemic inflammatory 
response. We acknowledge that further prospective studies are necessary to determine whether modifying the conduct of CPB relative to lactate levels will alter patient outcome.

\section{Limitations}

Because of the nonrandomized method of patient selection, there was a selection bias toward patients with more complicated congenital defects, with a higher mortality (study mortality rate $8 \%$ of 174 patients), which does not reflect our institutional mortality rate over that period (2.8\% for 1332 patients undergoing $\mathrm{CPB})$. Nonsurvivors in our study population had slightly higher lactate levels at baseline and a larger change during CPB than did survivors. This may reflect the preoperative clinical condition, diagnosis and complexity of the operation, and longer CPB and circulatory arrest times. Selection of higher risk patients may have increased the likelihood of correlating lactate content with adverse outcome.

In conclusion, our study reveals that an intraoperative increment in lactate level is an early and specific indicator of patients at high risk for morbidity and mortality after operations for congenital cardiac disease. Patient diagnosis, surgical complexity, and duration of circulatory arrest were associated with higher levels of lactate. Monitoring the lactate concentration during the phases of hypothermic CPB may be important, but further randomized studies relating specific changes in CPB management in response to a change in lactate level with patient outcome are necessary.

\section{REFERENCES}

1. Siegel LB, Hauser GJ, Hertzog JH, Hopkins RA, Hannan RL, Dalton HJ. Initial post-operative serum lactate predicts outcome in children after open heart surgery [abstract]. Crit Care Med 1995;23:A205.

2. Shemie SD. Serum lactate predicts postoperative complications after pediatric cardiac surgery [abstract]. Pediatr Res 1996;39: 54A.

3. Cheifetz IM, Kern FH, Schulman SR, Greeley WJ, Ungerleider RM, Meliones JN. Serum lactates correlate with mortality after operations for complex congenital heart disease. Ann Thorac Surg 1997;64:735-8.
4. Hatherill M, Sajjanhar T, Tibby SM, Champion MP, Anderson D, Marsh MJ, et al. Serum lactate as a predictor of mortality after paediatric cardiac surgery. Arch Dis Child 1997;77:235-8.

5. Duke T, Butt W, South M, Karl TR. Early markers of major adverse events in children after cardiac operations. J Thorac Cardiovasc Surg 1997;114:1042-52.

6. Jenkins KJ, Newburger JW, Lock JE, Davis RB, Coffman GA, Iezzoni LI. In-hospital mortality for surgical repair of congenital heart defects: preliminary observations of variation by hospital caseload. Pediatrics 1995;95:323-30.

7. Pollack M, Patel K, Ruttimann U. PRISM III: an updated pediatric risk of mortality score. Crit Care Med 1996;24:743-52.

8. Mizock BA, Falk JL. Lactic acidosis in critical illness. Crit Care Med 1992;20:80-93.

9. Lazenby WD, Ko W, Zelano JA, Lebowitz N, Shin YT, Isom OW, et al. Effects of temperature and flow rate on regional blood flow and metabolism during cardiopulmonary bypass. Ann Thorac Surg 1992;53:957-64.

10. Anand KJS, Phil D, Hansen DD, Hickey PR. Hormonal-metabolic stress response in neonates undergoing cardiac surgery. Anesthesiology 1990;73:661-70.

11. Anand KJS, Phil D, Hickey PR. Halothane-morphine compared with high-dose sufentanil for anesthesia and postoperative analgesia in neonatal cardiac surgery. N Engl J Med 1992;326:1-9.

12. Jonas RA. Flow reduction and cessation. In: Jonas R, Elliott M, editors. Cardiopulmonary bypass in neonates, infants and young children. Oxford: Butterworth-Heinemann Ltd; 1994. p. 67-81.

13. Haisjackl M, Birnbaum J, Redlin M, Schmutzler M, Waldenberger F, Lochs H, et al. Splanchnic oxygen transport and lactate metabolism during normothermic cardiopulmonary bypass in humans. Anesth Analg 1998;86:22-7.

14. Sicsic J-C, Duranteau J, Corbineau H, Antoun S, Menestret P, Sitbon P, et al. Gastric mucosal oxygen delivery decreases during cardiopulmonary bypass despite constant systemic oxygen delivery. Anesth Analg 1998;86:455-60.

15. Jonas RA. Neurological protection during cardiopulmonary bypass/deep hypothermia. Pediatr Cardiol 1998;19:321-30.

16. Rocke DA, Gaffin SL, Wells MT, Koen Y, Brock-Utine JG. Endotoxemia associated with cardiopulmonary bypass. J Thorac Cardiovasc Surg 1987;93:832-7.

17. Smith EEJ, Naftel DC, Blackstone EH, Kirklin JW. Microvascular permeability after cardiopulmonary bypass. J Thorac Cardiovasc Surg 1987;94:225-33.

18. Sheppard AP, Granger DN. Metabolic regulation of the intestinal circulation. In: Sheppard A, Granger D, editors. Physiology of the intestinal circulation. New York: Raven Press; 1984. p. 33-47.

19. Landow L, Phillips DA, Heard SO, Prevost D, Vandersalm TJ, Fink MP. Gastric tonometry and venous oximetry in cardiac surgery patients. Crit Care Med 1991;19:1226-33. 